\title{
Eficácia anestésica local da mistura enantiomérica de bupivacaína (S75R25) associada ou não à clonidina para anestesia caudal em crianças. Estudo comparativo com a bupivacaína racêmica (SR50)

\section{Instituto da Criança do Hospital das Clínicas, Faculdade de Medicina}

da Universidade de São Paulo, São Paulo

INTRロDUÇÃa

Atualmente, há uma tendência de se preferir os anestésicos locais isoméricos puros aos compostos racêmicos, como a SR50, justificada pela cardiotoxicidade potencial atribuída ao isômero $\mathrm{R}(+)$ e ao bloqueio motor residual no pós-operatório. A clonidina (Clo) tem sido utilizada associada a anestésicos locais com o objetivo de prolongar o bloqueio sensitivo (BS).

MÉTロDOS

Após aprovação pelo Comitê de Ética da instituição, 40 crianças, 5-10 anos, P1 e P2 (antigos ASA I e II) submetidas à anestesia geral para procedimentos infra-umbelicais de pequeno porte, foram aleatoriamente divididas em quatro grupos de acordo com as soluções administradas no espaço epidural sacro: SR50 + SF, SR50 + Clo, S75R25 + SF, S75R25 + Clo. Os anestésicos locais e a clonidina foram utilizados na dose de $1,75 \mathrm{mg} / \mathrm{kg}$ e $2 \mu \mathrm{g} / \mathrm{kg}$, respectivamente. O BS foi considerado o tempo entre a administração das soluções no espaço epidural sacro e a primeira dose de resgate analgésico (solicitado ou quando escores da escala objetiva para avaliação da dor (OPS) $\geq 6$ ). O BM foi avaliado pela escala de Bromage durante $8 \mathrm{~h}$ no pós-operatório. Todas as crianças receberam medicação pré-anestésica via oral com midazolam $(0,5 \mathrm{mg} / \mathrm{kg})$, anestesia geral com intubação traqueal (IOT) e monitorizadas (ECG-DII, oxímetro de pulso, pressão arterial não-invasiva e capnógrafo após a IOT). Realizou-se a análise estatística pela comparação dos grupos estudados utilizando a ANOVA e as variáveis estudadas por Kruskall-Wallis (BS e BM), onde $\mathrm{p} \leq$ 0,05 foi significante.

RESULTADIS

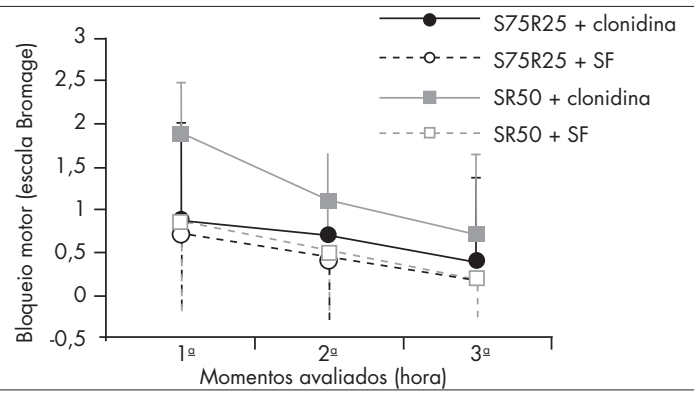

Figura 1. Bloqueio motor avaliado durante 8 h no pósoperatório.
Tabela 1. Intervalo (min) entre a punção e a primeira dose de analgésico

\begin{tabular}{|c|c|c|c|c|c|c|c|}
\hline Variável & Grupo & $\mathbf{n}$ & Mínimo & Máximo & Média & DP & p \\
\hline \multirow{4}{*}{$\begin{array}{l}\text { Intervalo } \\
\text { entre o } \\
\text { bloqueio e } \\
\text { a primeira } \\
\text { dose de } \\
\text { analgésico }\end{array}$} & $\begin{array}{l}\text { S75R25 + } \\
\text { clonidina }\end{array}$ & 10 & 348 & 1425 & 728,00 & 481,57 & 0,7398 \\
\hline & S75R25 + SF & 10 & 124 & 1427 & 715,50 & 505,90 & \\
\hline & $\begin{array}{l}\text { SR50 + } \\
\text { clonidina }\end{array}$ & 10 & 301 & 1427 & 901,80 & 440,55 & \\
\hline & $\mathrm{SR} 50+\mathrm{SF}$ & 10 & 127 & 1395 & 796,00 & 544,56 & \\
\hline
\end{tabular}

DISCUSSÃR

Os resultados deste estudo estão de acordo com escritos anteriores que utilizaram levobupivacaína e ropivacaína, comprovando que a diminuição do estereoisômero $\mathrm{R}$ da bupivacaína na S75R25 promove BS de duração semelhante ao da SR50. O BM foi significativamente maior somente no grupo SR50 + Clo durante a primeira hora de observação no pós-operatório. O BM residual é um efeito que a criança não consegue diferenciar da dor em sua avaliação, além de retardar a alta hospitalar e a satisfação dos pais com o procedimento.

CロNCLUSÃロ

SR50 e S75R25 foram semelhantes na eficácia como anestésicos locais para bloqueio caudal em crianças, em relação ao BS e BM. A associação de Clo promoveu aumento significativo do BM somente quando foi usada com SR50 e na primeira hora de observação no pós-operatório. A Clo na dose utilizada neste estudo não promoveu aumento do BS, não sendo observados efeitos adversos.

Locatelli B, et al. Br J Anaesth. 2005:94:366-71.

REFERÊNCIA

2. Ivani G, et al. Reg Anesth Pain Med. 2002;27:157-61.

Endereço para correspondência:

Emília A. Valinetti

R. Luis Góes, 1.328 - apto. 13

São Paulo (SP) - CEP 04043-150

E-mail:valinetti@ig.com.br ou emiliaav@icr.hcnet.usp.br 